\title{
Submission Guidelines
}

Bethlehem University Journal (ISSN 2410-5449) is a peer-reviewed scholarly journal published annually by the Office of the Dean of Research at Bethlehem University. BUJ (Bethlehem University Journal= the Journal) welcomes original articles on a variety of topics from different disciplines in both Arabic and English. BUJ encourages submissions that integrate contributions and research methodologies from multiple disciplines (interdisciplinary research).

BUJ also welcomes book reviews (should not exceed 1500 words) and review essays. Review essays examine a cluster of important books on a particular disciplinary or interdisciplinary topic, offering original and sustained arguments about new research developments and theoretical trends that would be of interest to our diverse readership.

\section{Publication Criteria}

\section{Manuscripts are accepted for publication under the following criteria:}

- The manuscript should present original and innovative research that observes sound methodology, correct documentation, correct grammar, and idiomatic language.

- The manuscript should follow the structure, organization, and order of the academic article in the relevant discipline, including introduction/ the conceptual context, problem statement, significance and scope of the research project, previous studies (literature review), research methodology, findings/ results, discussion, and recommendations.

- The manuscript should avoid ready-made introductions, flowery language, and journalistic writing styles, and should employ instead an analytical and theoretical style in developing the topic and demonstrating its originality.

- The manuscripts should contain an abstract that describes the aim of the study, its sample, and its main findings as well as 5-10 key words; the abstract should not include any citations or references.

- The manuscript include a Works Cited/ References list, organized in an alphabetical order, according to the style manual of the relevant discipline (APA, MLA, Chicago, etc.)

- The manuscript should maintain a clear correlation between the main results of the study and its title as well as its abstract. 
- The manuscript should observe all conventions about academic honesty and refrain plagiarizing any part of the study.

BUJ does not publish any articles that have been published and/or are under consideration elsewhere, including in electronic format or on any form on the internet.

The author(s) is solely responsible for the content of the manuscript. The ideas expressed in a manuscript are those of the author(s) and do not reflect the opinions of BUJ's Editorial Board or Office of Dean of Research at Bethlehem University.

\section{Double Blind Review and Acceptance Policy}

If the above criteria are met after the initial screening (quality control/ plagiarism check) of the relevant associate editor of the journal, manuscripts are submitted for a double-blind peer-review process by experts in the field (neither the reviewers of the articles nor the authors will have access to each other's identities).

Further the double-blind peer review process, the BUJ editorial board determines the suitability of the manuscript for publication in the journal-the submission can be accepted without revisions, rejected, or might be reconsidered for publication after major revisions. Final acceptance is granted only after the author(s) has completed all revisions to the satisfaction of all reviewers in the second round of double-blind peer review.

$\mathrm{BUJ}$ reserves the right to make any editorial changes that it deems necessary in preparing the manuscripts for publication and reserves the right NOT to publish any manuscript, without giving any justification and its decisions are final.

In the case an author withdraws his/her manuscript, the author shall incur all reviewing charges.

\section{Guidelines for Preparing the Manuscript}

\section{Style and Language}

BUJ considers articles in both English and Arabic for publication. Articles should be approximately 5000 words (about 15 double-spaced pages), including the Works Cited page. If images, tables, figures, or graphs are included, the size of each of the above should not exceed a half-page. 


\section{Text Formatting}

Manuscripts should be submitted in .doc or .rtf format (not pdf.); Traditional Arabic 14 for manuscripts written in Arabic or Times New Roman 12 for manuscripts written in English. Use A-4 paper size and 1-inch margins (or $2.5 \mathrm{cms}$ ) on all sides. Texts should be formatted with double spacing.

\section{Permissions and Fair Use}

The author is solely responsible for obtaining permission to use any quoted material that appears in the submission, in the case the material exceeds fair use standards.

\section{Images, Tables, and Graphs}

If the manuscript includes figures, tables, graphs, or images, the author should insert these figures or images in their correct place in the text and add appropriate captions. These images and figures should be $300 \mathrm{dpi}$, at least, high resolution, with a width of 4.25 inches.

\section{Documentation and Citations}

Authors should select the documentation style that is used in their discipline. Regardless of the documentation style selected, authors should be consistent in their documentation and citation throughout the whole manuscript.

- The list of References or Works Cited should be placed at the end of the manuscript and should be ordered alphabetically.

- Only sources that are cited in the text should be included in the list of References/ Works Cited.

- BUJ does not recommend the use of Footnotes or Endnotes for subsidiary information in the text; use all essential information in the text itself.

\section{Acknowledgments}

All articles should have a funding acknowledgment statement and the names of all funding organizations should be stated in full. Acknowledgments of funding should be placed before the reference list.

\section{Disclosure and Conflict of Interest}

Authors, reviewers or editorial staff have to disclose any financial or potential conflict of interest that might compromise the integrity of the publication process. 


\section{Academic Honesty/ Plagiarism}

Every manuscript is submitted for a plagiarism check in the initial screening. Authors should observe all conventions for academic honesty and avoid plagiarism, in all its forms, as it constitutes an unethical practice and is unacceptable. With the submission, authors declare the originality of their work, properly citing, re-using or copying previous publications.

If plagiarism is detected during the peer review process, the manuscript may be rejected. If plagiarism is detected after publication, BUJ has the right to issue a correction or retract the paper.

\section{Submission Procedure}

For your submission to be complete, please send all of the following:

- An electronic copy in Word or WordPerfect document, not in a PDF,

- to the Bethlehem University Journal (buj@bethlehem.edu).

- A cover note, including the title of the manuscript, the author's name, affiliation, academic rank, and contact information (mailing address, email address, and phone number).

- The note should also include a declaration that "The article has not been published or sent for publication elsewhere."

\section{Offprints}

BUJ does not present honoraria for authors of accepted manuscripts. However, BUJ provides the corresponding author one hard copy of the volume of the journal in which the manuscript appears at no cost. 